\title{
QUALITATIVE AND QUANTITATIVE ASPECTS OF OPERATIONAL BANKING RISK IN ROMANIA
}

\author{
Associate Professor PhD Adela Socol, e-mail: adelasocol@yahoo.com \\ "1 Decembrie 1918” University of Alba Iulia
}

\begin{abstract}
The purpose of this paper is to present the quantitative and qualitative aspects of operational banking risk to the level of Romanian banking societies. The study focuses on the implementation and maintenance of an operational banking risk management framework. The paper is organized as follows: first, it describes the operational banking risk. Second, the paper presents the means through the banks quantify the operational banks. Third, it is present the challenges of measurement of the operational banking risk for supervisory authority and banks. The active banks in Romania must determine their capital necessary for covering the operational risk using one of the three means of quantification mentioned by the Basel II Agreement, assumed by the Capital Adequacy Directive and by the national legislation - the National Romanian Bank's regulation regarding the operational risk: the Basic Indicator Approach, the Standardized Approach and Advanced Measurement Approaches. Banks may choose one of the three methods mentioned above.
\end{abstract}

The Basel II Capital Agreement, the name of the International Convergence of Capital Measurement and Capital Standards - a Revised Framework, has been finalized by the Basel Committee and has been signed in November 2005. The Basel II Agreement doesn't have an imperative character for any national state; it is just a guiding frame for adopting the specific national legislations. As for the countries part of the European Union, the Basel II settlements had been the base for configuring the European Directive adopted under the name of Capital Requirements Directive CRD by the Council and European Parliament in June 2006. The directive represents in fact the combination of two directives: Directive 2006/48/EC regarding the building and activity of the credit institutions (revised) and the Directive 2006/49/EC regarding the capital adequacy of the investments societies and credit institutions (revised). European Union's member states must transpose the settlements of the Directive CDR and the credit institutions have to apply them starting with the beginning of 2007. Romania's adhesion to the European Union from January the $1^{\text {st }} 2007$ brings the obligation to enforce the communitarian regulations in our banking system, too. But, credit institutions can choose between the present settlements of the first Basel I Agreement and the first or average approaches of the new Basel II Agreement. The most sophisticated approaches of the new agreement (advanced approach IRB for the credit risk and AMA approach for the operational risk) will be available from the year 2008, when all credit institutions from the European Union will have to apply the Basel II Agreement.

The New Agreement defines the two concepts in part V, point 644 like this: operational risk is defined as the risk of loss resulting from inadequate or failed internal processes, people and systems or from external events. This definition includes legal risk, but excludes strategic and reputation risk. Legal risk includes, but is not limited to, exposure to fines, penalties, or punitive damages resulting from supervisory actions, as well as private settlements.

In Romania, the minimal structure of the significant banking risks is presented by the National Romanian Bank's Regulation no.17/2003 regarding the organization and internal control of the credit institutions' activity and management of the significant risks, the organization and development of the internal audit in the credit institutions, published in the Official Monitor of Romania no.47/2004. Regarding the operational risk, it is defined as the national settlement as the 
risk of getting losses or not realizing the estimated profits, being determined by internal factors (the inappropriate development of some internal activities, the existence of inadequate people or systems) or external factors (economic conditions, changes in the banking environment, technological progresses). The legal risk is a component of the operational risk, arising due to not applying or defectively applying the legal or contractual regulations and negatively influences the operations or the credit institutions' situation.

In 2006 the European regulations according to Basel II Agreement were adopted in Romanian national legislation. The competent national authorities - National Romanian Bank, National Committee for Exchange Securities and Public Finance Ministry - prepared the national settlements according to Basel II Agreement. Consequently, it was adopted in December 2006, the Urgent Ordinance of Government no. 99/2006 regarding the credit institutions' activity and the capital adequacy. The regulation mentioned above has advantage to be a guide for all the credit institutions and societies for financial investments. In completion of primary legislation, in the same period were adopted the secondary regulations with technical aspects. The new national framework came in force from January the $1^{\text {st }} 2007$.

According to the New Basel II Agreement the banking companies must accomplish specific capital requirements regarding the total credit, market and operational risk. The capital ratio is calculated using the definition of regulatory capital and risk-weighted assets and must be no lower than $8 \%$, according to the 40 article from the Basel II Agreement:

$$
\text { Total Amount of Capital/Risk - Weighted Assets } \geq 8 \%
$$

In the Basel II approach, average assets risk-weighted must include capital requirements for covering the operational risk. The solvency ratio (expressing the proper funds as a ratio of total assets and elements outside the balance, net of provisions, adjusted according to the risk degree), though it has registered a certain recession in the past years, is maintained at a high level (21,1\% at the end of 2005 and 17,3\% at the end of 2006), much higher than the minimum imposed by the banking prudence regulations applicable in Romania (12\%) and also than the minimum admitted by the European and international regulations $(8 \%)$.

The active banks in Romania must determine their capital necessary for covering the operational risk using one of the three means of quantification mentioned by the Basel II Agreement, assumed by the Capital Requirements Directive CRD and by the national legislation - the National Romanian Bank's regulation regarding the operational risk: the Basic Indicator Approach, the Standardized Approach and Advanced Measurement Approaches. Banks may choose one of the three methods mentioned above.

The first approach - the Basic Indicator Approach can be used by any bank, without being necessary the fulfilling of some extra requirements or the obtaining of approvals. Banks can calculate the necessary of capital for covering the operational risk applying the Standardized Approach only after a pre-available approval from the Supervising Direction of the Romanian National Bank. For obtaining the pre-available approval from the central bank, a bank must transmit to the Supervising Direction of the Romanian National Bank documentation in the shape of a selfvaluation, through which they prove the fulfillment of certain specific criteria:

a) Banks must have a well-documented system of identification, valuation and management of the operational risk, with precise and well-delimited responsibilities. This system must receive an internal validation and must be independently and regularly examined, at least once a year and also as many times as the objective conditions impose this fact.

b) Banks must provide for the identification of exposal to operational risk and the monitoring of relevant information and data regarding the operational risk, including those referring to the significant losses. 
c) Banks must provide the integrity of the system of valuating the operational risk in the risk managing processes existing in the institution. The results of the operational risk valuation must be a part in the process of monitoring and controlling the operational risk profile in the institution.

d) Banks must implement a system of internal reporting to provide periodically, but at least yearly, the supply of reports regarding the operational risk for the relevant structures and persons inside the entity.

Credit institutions can determine the capital requirement for covering the operational risk through applying the Advanced Measurement Approaches only after was obtained the pre-available approval for using an internal model, from the Supervising Direction of the Romanian National Bank. Obtaining this approval supposes presenting by the credit institution of the Romanian National Bank of a specific documentation referring to a qualitative and quantitative standards set.

In the case in which a credit institution or a financial investments services company, Romanian juridical person, is a mother-company at the European Union's level, branch of a credit institution - mother, respectively an investments company - mother at the European Union's level or branch of a holding financial company - mother at the European Union's level and if it is intentioned the use at the group level of the advanced evaluation approach of the operational risk, every approval request addressed to the Romanian National Bank must be accompanied by a specific documentation, and by a description of the methodology used for capital allocation for the operational risk between the entities from the group. The request will indicate also if the manner in which is intended to include the effects of diversification in the quantifying system of the operational risk.

Using the Advanced Measurement Approaches combined with the other approaches (the basic approach, be it with the Standardized Approach or with the Alternative Standardized Approach) is possible only with the agreement of the Supervising Direction of the Romanian National Bank's approval and if there are fulfilled the following conditions:

a) The use of the approaches provides the covering of all the operational risks that a bank is exposed to;

b) The approaches applied in different activities, geographic locations, juridical structures or other relevant divisions established at an internal level are considered adequate by the National Romanian Bank;

c) There are fulfilled the criteria of being eligible for those parts of activity in which there is applied, in each case, the Standardized Approach, the Alternative Standardized Approach or the Advanced Measurement Approach;

d) At the implementation of the Advanced Measurement Approach, a significant part of the bank's operational risks is covered by this approach;

e) The bank assumes that it will gradually implement the Advanced Measurement Approach, so that a substantial part of its operations to be covered by this approach in a period of time agreed by the National Romanian Bank.

As regards the combined use of the approaches to determine the capital requirement in a group, in Romania we face with the following situation: 
Table 1.

The combined use of the approaches in order to determine the capital requirement at the group's level.

\begin{tabular}{|l|c|c|c|}
\hline \multicolumn{1}{|c|}{$\begin{array}{c}\text { The approach used by the } \\
\text { subsidiary }\end{array}$} & \multicolumn{2}{|c|}{ The approach used in the group } \\
\cline { 2 - 4 } & Basic Approach & $\begin{array}{c}\text { Standardized Approach or } \\
\text { Alternative Standardized } \\
\text { Approach }\end{array}$ & $\begin{array}{c}\text { Advanced Measurement } \\
\text { Approach }\end{array}$ \\
\hline $\begin{array}{l}\text { At the subsidiary level we use the } \\
\text { Basic Approach }\end{array}$ & - & Partial using is accepted. & Partial using is accepted. \\
\hline $\begin{array}{l}\text { At the subsidiary level we use the } \\
\text { Standardized Approach or } \\
\text { Alternative Standardized Approach }\end{array}$ & $\begin{array}{c}\text { Partial using is not } \\
\text { accepted. }\end{array}$ & Partial using is accepted. \\
\hline $\begin{array}{l}\text { At the subsidiary level we use the } \\
\text { Advanced Measurement Approach }\end{array}$ & Partial using is accepted. & Partial using is accepted. & \\
\hline
\end{tabular}

\section{The Basic Indicator Approach.}

Banking societies must permanently have funds for covering the operational risk to which they are exposed. In the framework of the Base Indicator Approach calculating the capital required for covering the operational risk is done by applying the $15 \%$ quota upon a relevant indicator determined according to the methodology exposed below. The relevant indicator is calculated as an arithmetic average of the annual gross results of the bank's activity recorded by the credit institution in the last three ended financial exercises.

Banks using the Basic Indicator Approach must hold capital for operational risk equal to the average over the previous three years of a fixed percentage (denoted alpha) of positive annual gross income. Figures for any year in which annual gross income is negative or zero should be excluded from both the numerator and denominator when calculating the average. The charge may be expressed as follows:

$$
K_{B I A}=\left[\sum\left(G I_{1 \ldots N} \times \alpha\right)\right] / N,(2)
$$

where:

$K_{B I A}=$ the capital charge under the Basic Indicator Approach;

$\mathrm{GI}=$ annual gross income, where positive, over the previous three years;

$\mathrm{N}=$ number of the previous three years for which gross income is positive;

$\alpha=15 \%$, which is set by the Committee, relating the industry wide level of required capital to the industry wide level of the indicator.

The gross result of the banking activity is determined as an algebra sum of some specific elements based on the elements from the profit and losses account at December 31, audited.

The negative or null values of the annual gross result, if such situations appear, are not considered in calculating the relevant indicator. In such cases, the relevant indicator is calculated through reporting the positive values' sum of the annual gross result to the number of years in which bigger than zero values has been recorded.

If the credit institution does not have the necessary data in an audited form, we will use the estimations of those data.

In calculating the annual gross result we are including the following specific elements, having the signification of the elements from the profits and losses account of the credit institution realized according to the Romanian Settlements from 22/12/2005 - Accounting Settlements according to the European Directives applied to the credit institutions: Interest income and assimilated income, inclusively from debentures and other fixed income bonds; Interest expense and assimilated expense; Income from shares and other variable income securities; Commission income; Commission expense; Net profit/ (loss) from financial operations; Other operating income. 
In determining the annual gross result of the component elements like incomes or profits we are considering them positive, and the expenses or losses we consider them negative. In determining the annual gross result of the banking activity the following aspects are taken into consideration:

- Valuation procedures.

- Calculating the annual gross result of the banking activity is done before deducting the provisions and other exploitation expenses. In the exploitation expenses are included the expenses with the externalized activities to other parts, in the situations in which that part is not the mothercompany or a filial of the mother-company - credit institution. The credit institutions can deduct the expenses related to the externalized activities in the situation in which the externalized services providing institution is respecting the prudential requirements applied to the credit institutions in Romania or some equivalent prudential requirements.

- There are not included in the calculating procedure of the annual gross result of the banking activity the profits or losses resulted from the selling of the elements not-included in transaction portfolio, extraordinary incomes and assurances' incomes.

- Sums representing corrections upon the value of the elements included in the transaction portfolio can be included in the calculating procedure of the annual gross result, if they are found in the profits and losses account. Corrections upon the value of the transaction titles that are found on the profits and losses account must be included in the calculating procedure of the annual gross result.

The current model in which is elaborated Account of profits and miss in Romania permits the identification to all the necessary elements of the settlement of crude annual result, depending on which is established the prerequisite for extreme the covering risk operationally. This means that which banks makes ones choice for base approach in the quantification risk operationally, aren't obliged to achieve adjacent situations. The banks dispose of the primary information for the determination of the requirement of capital concerning the operational risk, on the strength of account of profit and miss.

\section{The Standardized Approach.}

In According to the Standardized Approach, banks' activities are divided into eight business lines. Banking societies have to group their activity on the eight activity lines: Corporate finance, Trading and sales, Retail banking, Commercial banking, Payment and settlement, Agency services, Asset management, Retail brokerage.

Yearly financial situations of an active banking society from Romania (especially the balance sheet, profit and losses account, situation of modification of the self capitals, situation of the cash-flows and the explicative notes), as they are established presently by the legal settlements (Settlements from December 222005 regarding the European directives, applicable to the credit institutions, approved through Romanian National Bank Order no. 5/2005, published in Romanian Official Monitory no. 1182/2005) do not contain the detailed activities of the bank on the activity lines requested by the settlements according to the Basel II Agreement. In such context, every banking society which wants the quantification of the banking operational risk through standard approach is obliged to configure its evidence system of the operations, based on which it can identify the eight activity lines according to the Basel II Agreement settlements.

Such a system can't be operational and efficient only though an integrated informatics application, of the level of the entire banking society, as well as at the level of the Central unit, as at the level of each territorial operative banking unit.

Because the measurement of the banking operational risk in standard approach imposes to the bank to establish the yearly gross incomes on activity lines from the last three years, the banking society must act post factum in grouping the activities on lines, for at least three financial closed exercises. 
Grouping the activities developed by a banking society on activity lines, according to the requests from the standard approach of the operational risk, represents a difficult exercise for the bank. Information from the yearly financial situations that the bank is disposing does not allow it to classify the banking activities on lines, only after detailed analyzes.

For each of the activity lines, the banking society must establish the gross income, for the last three financial exercises closed. For this there are used information from the profits and losses account, which are presenting the expenses and incomes of the banking societies. Only that, the format of the profits and losses account of the active banking societies from Romania does not contain the activity lines settled by the Basel II Agreement.

Standard approach of the banking operational risk does not suppose sophisticated calculus for the banking units. The difficulties are related of identifying correctly the activity lines. Once established the yearly gross incomes for each activity line, it proceeds to effective calculating the needed capital for covering the operational banking risk.

Within each business line, gross income is a broad indicator that serves as a proxy for the scale of business operations and thus the likely scale of operational risk exposure within each of these business lines. The capital charge for each business line is calculated by multiplying gross income by a factor (denoted beta) assigned to that business line. Beta serves as a proxy for the industry-wide relationship between the operational risk loss experience for a given business line and the aggregate level of gross income for that business line. It should be noted that in the Standardized Approach gross income is measured for each business line, not the whole institution, i.e. in corporate finance, the indicator is the gross income generated in the corporate finance business line.

The total capital charge is calculated as the three-year average of the simple summation of the regulatory capital charges across each of the business lines in each year. In any given year, negative capital charges (resulting from negative gross income) in any business line may offset positive capital charges in other business lines without limit.

However, where the aggregate capital charge across all business lines within a given year is negative, then the input to the numerator for that year will be zero. The total capital charge may be expressed as:

$$
K_{T S A}=\left\{\sum_{\text {years: } 1-3} \max \left[\sum\left(G I_{1-8} \times \beta_{1-8}\right), 0\right]\right\} / 3,
$$

Where:

$\mathrm{K}_{\mathrm{TSA}}=$ the capital charge under the Standardized Approach

$\mathrm{GI}_{1-8}=$ annual gross income in a given year, as defined above in the Basic

Indicator Approach, for each of the eight business lines

$\beta_{1-8}=$ a fixed percentage, set by the Committee, relating the level of required capital to the level of the gross income for each of the eight business lines.

The values of the betas are: Corporate finance $18 \%$, Trading and sales $18 \%$, Retail banking $12 \%$, Commercial banking 15\%, Payment and settlement 18\%, Agency services 15\%, Asset management $12 \%$, Retail brokerage $12 \%$.

The elements of the profits and losses account of the active banking societies from Romania do not offer sufficient information for calculating the gross income on activity lines. That is why necessary the information corroboration with the ones was obtained from the explicative notes of the yearly financial situations of the studied society. Legislation in Romania appreciates that for each significant element from the yearly financial situations must exists information in the explicative notes (article 119 from the Settlements from December 222005 regarding the European directives, applicable to the credit institutions, approved through Romanian national Bank order no. 5/2005, published in Romanian Official Monitory no. 1182/2005). Without considering until the present day the settlements of the Basel II Agreement, the banking societies present in the 
explicative notes detailed of the expenses and incomes, difficult of framing in the banking activity lines specific to the standard approach of the banking operational risk.

\section{The Alternative Standardized Approach.}

By applying the alternative standardized approach, banks are able to find out the capital requirement for covering the operational risk, if they receive the previous approval of the National Bank of Romania's Surveillance Head Office. A bank may apply this type of approach of the operational risk if it carries on mainly retail banking business and/or commercial banking business, the obtained incomes being at least $90 \%$ of the bank's total incomes.

The methodology for determining the capital requirement for covering the operational risk using the alternative standardized approach is the same as for the standardized approach, except the two business lines: Commercial banking and Retail banking, for them the annual gross income is replaced by an alternative indicator for the normalized income, equal to 0,035 of the medium annual volume of loans and advances according to this two business lines, estimated on the basis of the data from the last three financial years.

\section{The Advanced Measurement Approach.}

Advanced Approach Measurements represents a set of operational banking risk's quantification methods, found in the Basel II Agreement. Advanced evaluation approach in quantifying the banking operational risk is not an accessible method to any credit institution, including also active banking company from Romania. On the other hand, banking companies are discouraged in applying this method by the complexity of evaluating methods, and on the other hand, by the restrictions imposed by the national supervising authority - Romanian National Bank, in applying these methodologies of quantifying the operational banking risk.

So, according to the 33 article from the Romanian National Bank Regulation regarding the operational risk, institutions that are applying before January 1st 2010 the advanced evaluation approach for determining the capital requirement for the operational risk must have, during the year 2008 and 2009 total self funds at a higher level than $90 \%$ respectively $80 \%$ from the total self funds necessary that could result by applying the available settlements before January 2007 .

In determining the capital requirements for covering the operational risk, institutions include also the expected and un-expected losses, so:

$$
\text { Capital Charge under AMA }\left(\mathrm{CC}_{\mathrm{AMA}}\right)=\text { Expected Loss (EL) + Unexpected Loss (UL) (4) }
$$

If ELs are already captured in a bank's internal business practices, then capital charge set at the unexpected loss alone:

$$
\text { Capital Charge under AMA }\left(\mathrm{CC}_{\mathrm{AMA}}\right)=\text { Unexpected Loss (UL) (5) }
$$

In AMA approach, there is no specification regarding the analytic approach that has to be used by the banking companies. However, banks must demonstrate that their measurement system is sufficiently "granular" to capture severe tail loss events, e.g 99.9\% VaR. quantifying the operational banking risk must include also the low frequency risk events and with potential major negative effect, situate given by the extremity of the statistic distribution curve, so that it will assure a rigorously standard compared to the a trust interval of $99,9 \%$ for a year time horizon.

Regarding the achievement of the mentioned rigorously standard, the operational risk quantification system of an institution must include a series of essential criteria, among which at least: internal data use, external data use, scenario analysis and business factors use and the internal control system. A bank needs to have a credible, transparent, well-documented and verifiable approach for weighting these fundamental elements in its overall operational risk measurement system. In such cases, scenario analysis, and business environment and control factors, may play a more dominant role in the risk measurement system. The correlations between the losses estimations from the operational risk can be recognized only if the institution can demonstrate 
adequately in the Romanian National Bank's opinion or of the National Committee of Values, which the correlation measurement systems are rigorously, are correctly implemented and take into consideration the incertitude level corresponding to such estimations, especially in the crisis periods. Institution must validate the hypothesis referring to the correlations by using corresponding quantitative and qualitative techniques. The operational risk quantification system must be well preserved on the internal plan and it must be avoided taking into consideration for more than one time the positive results of the qualitative evaluation or the diminution of the risk techniques, which have already recognized in other segments of the capital adequacy framework.

Operational risk quantifications generated by the institution must be substantiated on a historical observation period of at least five years. In the case in which an institution applies for the first time the advanced approach of quantifying the operational risk it can be accepted a historical observation period of minimum three years. For applying the advanced evaluation approach in quantifying the operational risk, a credit institution must have the capacity of splitting the internal historical data regarding the operational risk on some activity lines and loss events' categories and can send these data to the Romanian National Bank, on its request. There are eight activity lines set through the Romanian National Bank's Regulation regarding the operational risk and they are according to the Basel II Agreement: financing the commercial companies, transactions and sells, retail brokerage, commercial banking activity, retail banking activity, payments, agent services and assets' management. There are seven types of operational banking risk generator activities specified by the Romanian National Bank's Regulation regarding the operational risk and they are adapted after the Basel II Agreement: internal fraud, external fraud, employment practices and working place safety, clients, products and business practices, damages upon the corporal assets, activity breaking and inappropriate functioning of the systems, execution, delivery and processes' management. Criteria of allocating the losses on activity lines and on events' categories must be objective and well documented.

It's obvious that none of the Romanian active banks intend to apply the Advanced Measurement Approaches in managing the operational risk in the near future. Banks are discouraged in applying this approach because the banks internal historical data regarding operational risk generating events either don't exist or are insufficient. And the external potentially operational risk generating events must be adequately estimated, and for this a bank needs adequate risk parameters. It is very difficult for a bank to estimate the probability and the impact of the banking operational risk generating events. The probability and impact of the risk events measuring scales (regarding the financial outcomes, strategic objectives, and the bank's reputation) are, in essence, subjective.

\section{Bibliography:}

Havlický, Jiry (2006): Quantification of Operational Risk Loss within the „Loss Distribution Approach", address given at the 3rd International Conference Managing and Modelling of Financial Risk, $6^{\text {th }}$ - 7th September 2006, Technical University of Ostrava, Faculty of Economics, Department of Finance,

Czech.Basel Committee on Banking Supervision (2006) Observed range of practice in key elements of Advanced Measurement Approaches (AMA), October 2006, BIS, Basel, Switzerland,

http://www.bis.org/publ/bcbs131.htm

Basel Committee on Banking Supervision (2006) Basel II: International Convergence of Capital Measurement and Capital Standards: A Revised Framework, June 2006, BIS, Basel, Switzerland, http:// www.bis.org/publ/bcbs128.htm

National Bank of Romania (2006) Report on Financial Stability for the Year 2006, May 2006, http://www.bnr.ro/publicații/Raport_asupra_stabilităţii_financiare

Basel Committee on Banking Supervision (2002) The 2002 Loss Data Collection Exercise for Operational Risk: Summary of the Data Collected, March 2003, BIS, Basel, Switzerland, http://www.bis.org/bcbs/qis/ldce2002.pdf 